ISSN: 0719-3726

\title{
Radiologic findings consistent with kissing spines syndrome in Chilean thoroughbreds horses
}

\section{Hallazgos radiológicos correspondientes a síndrome kissing spines en caballos FSC en Chile}

\author{
Darío Infante $^{\mathrm{a}}$, Arnaldo Croxatto ${ }^{\mathrm{b}}$, Felipe Corrêa $^{\mathrm{b}, \mathrm{c}_{*}}$ \\ ${ }^{\mathrm{a} U n i v e r s i d a d ~ M a y o r, ~ H o s p i t a l ~ D o c e n t e ~ V e t e r i n a r i o ~-~ H i p o ́ d r o m o ~ C h i l e . ~}$ \\ ${ }^{b}$ Escuela de Medicina Veterinaria, Facultad de Ecología y Recursos Naturales, Universidad Andres Bello, \\ República 440, Santiago, Chile. \\ ${ }^{c}$ Programa de Doctorado en Medicina Veterinaria, Facultad de Ecología y Recursos Naturales, Universidad \\ Andres Bello. \\ *Autor de correspondencia: felipe2983@gmail.com
}

\begin{abstract}
SUMMARY
Alterations in the thoracolumbar spine of racehorses are frequent and often they significantly decrease the athletic performance of affected horses. The most common thoracolumbar alteration in thoroughbred horses is kissing spines syndrome (KSS). The narrowing of the interespinous space, generally located between T14-T15 and T15-T16, produces this syndrome. A radiographic study was performed at 30 thoroughbred horses on the segment between T12 and T18. Two latero-lateral views of the T12 to T18 segment were taken with a digital equipment to each horse. The images were analyze and the radiographic findings established the KSS according to a grading scale. The study sample was homogeneous and the results were similar to other radiographic findings of KSS occurring in segments T14-T15 and T15-16.
\end{abstract}

Key words: horse; kss; kissing spines; radiology.

\section{RESUMEN}

Los caballos de deporte frecuentemente presentan alteraciones de la columna toracolumbar, las cuales disminuyen su rendimiento deportivo. La alteración toracolumbar más frecuente en los caballos de la hípica es el síndrome kissing spines (SKS). Este síndrome se produce por el estrechamiento del espacio entre las apófisis espinosas del segmento toracolumbar, con mayor frecuencia entre T14-T15 y T15-T16, y su diagnóstico se 
ISSN: 0719-3726

realiza mediante imagenología. El presente estudio fue realizado en una muestra de 30 caballos FSC. Se obtuvieron 2 vistas radiológicas digitales, latero-laterales, del segmento T12 a T18 para analizar los hallazgos radiológicos correspondientes a SKS. La muestra del estudio fue homogénea y los resultados son similares, encontrándose más hallazgos radiológicos de SKS en los segmentos T14-T15 y T15-16.

Palabras clave: caballo; SKS; kissing spines; radiología.

\section{INTRODUCTION}

Diseases affecting the back of horses are divided into 3 categories: congenital deformities, soft tissue injuries and spinal injuries; KSS is the most common disorder in sport horses in this last category (Jeffcott, 2005).

Kissing spine syndrome is a condition characterized by a narrowing of the space between spinous processes, and the modification of their dorsal margins. The most common location of the lesion in the thoracic segment is between T10-T18 and between L1-L6 in the lumbar segment (Denoix \& Dyson, 2010).

The etiology of KSS is multifactorial, making it difficult to diagnose during its development (Butler et al., 2008). It also occurs in horses with low or normal athletic performance and with poorly defined clinical signs, because the presentation of pain may be continuous, intermittent or absent (Henson \& Kidd, 2009).

A study carried out by Turner (2011) in 310 horses, reported an incidence of $68 \%$ of horses presenting $\mathrm{KSS}$; however, the diagnosis rate has been reported in only $0.9 \%$, which implies that it is highly underdiagnosed (Henson \& Kidd, 2009).

Radiographic evaluation of the distance between DSPs and the equine thoracolumbar segment allows diagnosis using a grading system, which goes on a scale from 0 to 7 . This is necessary to determine clinical and/or surgical treatments (Butler et al., 2008).

The aim of this study was to describe radiological signs corresponding to KSS in thoroughbred horses in Chile. For this purpose we described radiological signs, grade of KSS, distribution at the thoracic segment and the correlation between body weight and grade of KSS.

\section{MATERIALS AND METHODS}

For this study, 30 thoroughbred horses were selected with no age range defined. They were grouped into 10 stallions, 10 geldings and 10 mares. Two radiographic views were obtained for each horse of the segment T12-T18 by lateral-side views, with a technique of $70 \mathrm{kV}$ and $90 \mathrm{~mA}$ (Berner et al., 2012). The chassis was located on the right side of the horse, according to the aforementioned location, and the laser beam of the $\mathrm{x}$-ray equipment was positioned $10-15 \mathrm{~cm}$ below to the upper edge of the spinous process ridges, on the left side of the horse. 
ISSN: 0719-3726

To grade KSS from 0 to 7, each radiographic view was analyzed according to the grading scale proposed by Zimmerman et al. (2012). Radiographic images were classified in different grades considering interosseous space width in millimeters and degrees, increased opacity, radiolucency and remodeling of the dorso/craneal aspect.

Statistical analysis: the results of this study were expressed as Average \pm Standard Deviation (SD) or as relative frequencies (\%). For statistical analysis, Graph Pad version 5.0 was used. In each analysis, KolmogorovSmirnov normality test was performed in order to determine the distribution of data. To find significant differences, Analysis of Variance test (ANOVA) was performed. The multiple comparison Kruskal-Wallis posttest was used with the data obtained with non-parametric distribution (grade) and the multiple comparison Siegel-Tukey test was used in the data obtained with parametric distribution ( $\mathrm{mm}$ and $\mathrm{kg}$ ), to identify statistically significant differences between groups. Finally, Spearman's correlation coefficient was evaluated between body weight and grade of KSS, to determine their degree of association. $\mathrm{p}<0.05$ was considered as a criterion of significance for these analysis.

\section{RESULTS}

Among the groups under study, no significant differences were found in the evaluated radiological signs. However, there is a mathematical tendency to have higher average width in millimeters of the interspinous space in the group of geldings in all interespinous spaces (Table 1, Figure 1).

Table 1: Interspinous space in millimeters (mean \pm S.D) in all studied groups.

\begin{tabular}{l|l|l|l} 
& Stallions & Geldings & Mares \\
\hline T12 - T13 & $8.3 \pm 5.5$ & $8.6 \pm 5.2$ & $6.3 \pm 2.5$ \\
T13 - T14 & $6.8 \pm 3.9$ & $8.7 \pm 6.5$ & $4.1 \pm 3.0$ \\
T14 - T15 & $6.8 \pm 3.9$ & $8.7 \pm 6.5$ & $4.1 \pm 3.0$ \\
T15 - T16 & $5.4 \pm 4.8$ & $6.2 \pm 4.9$ & $5.1 \pm 3.1$ \\
T16 - T17 & $7.3 \pm 3.0$ & $9.7 \pm 2.9$ & $7.2 \pm 5.0$ \\
T17 - T18 & $8.2 \pm 2.9$ & $10.0 \pm 2.5$ & $8.1 \pm 5.8$
\end{tabular}




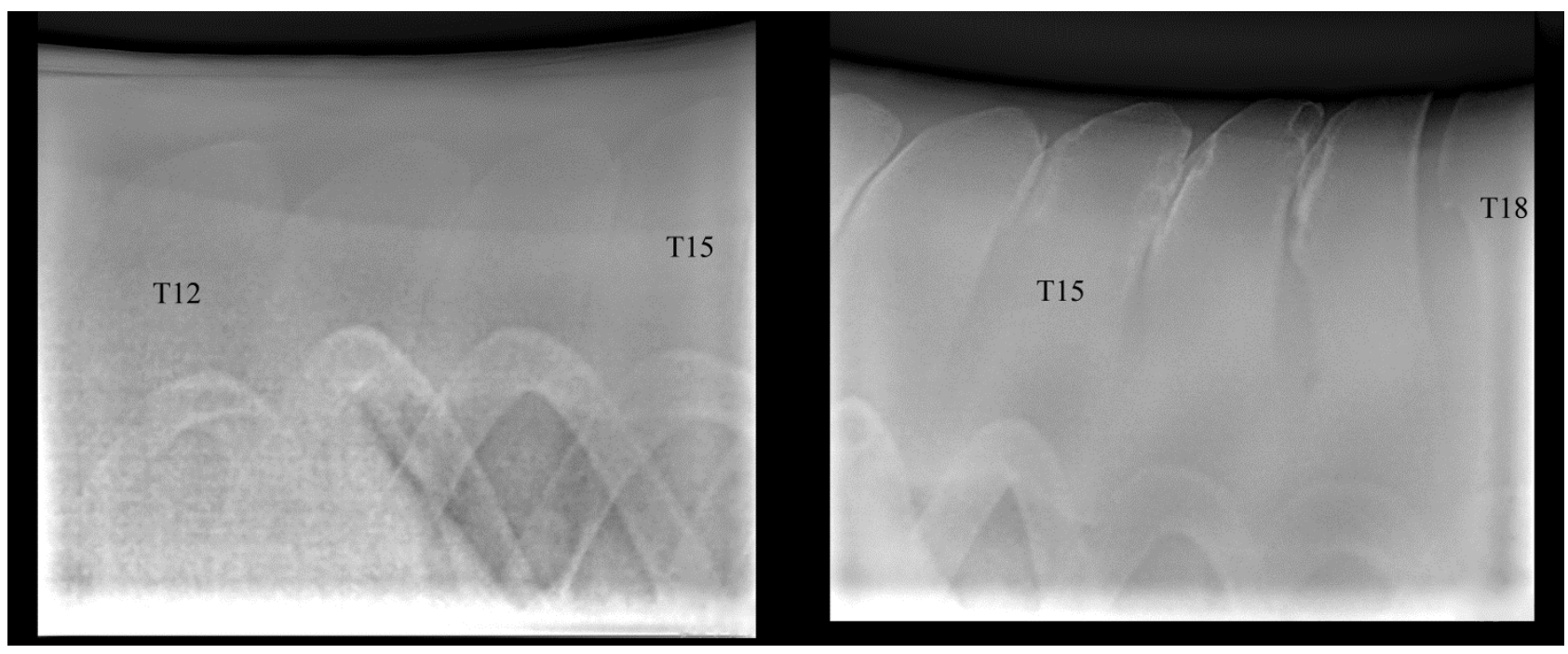

Figure 1. Latero-lateral radiographic views of T12 - T18 in one of the geldings of the study. It can be observed KSS grade 1 (T12-T13), 5 (T13-T14), 6 (T14-T15), 6 (T15-T16), 0 (T16-T17) and 0 (T17-T18).

There is also no significant difference in the grade of KSS. However, stallions and mares have a higher degree of KSS in the T14-T15 and T15-T16 segments. Geldings have a higher degree of the syndrome in the T15-T16 segment. In addition, the end segments have a lower graduation in comparison with the central segments.

Stallions and mares presented on average 4 affected DSPs, unlike geldings that presented on average 3.5 affected DSPs.

In the group of stallions, a significant difference $(\mathrm{p}<0.05)$ between body weight and grade of KSS was found in the T13-T14 ( $\mathrm{p}=0.0045)$ and T15-T16 ( $\mathrm{p}=0.0108)$ segments, but in the geldings group a significant difference was not found. However, the correlation between body weight and grade of KSS in stallions (Figure 2) and geldings (Figure 3) has a negative slope. In the group of mares a significant difference between body weight and grade of KSS in T14-T15 ( $\mathrm{p}=0.0108)$ segment was found. The correlation between body weight and grade of KSS in mares has a positive slope (Figure 4). 


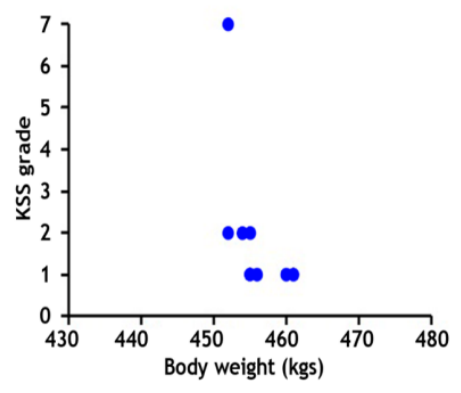

Figure 2. Correlation between body weight and grade of KSS in stallions.

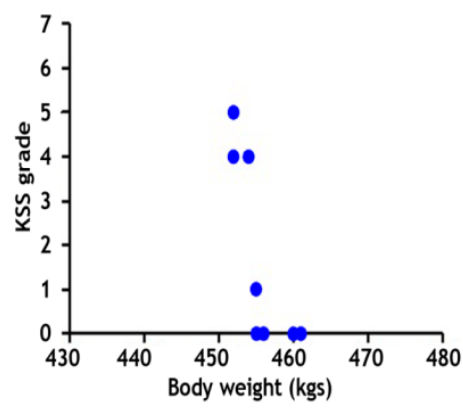

Figure 3. Correlation between body weight and grade of KSS in geldings.

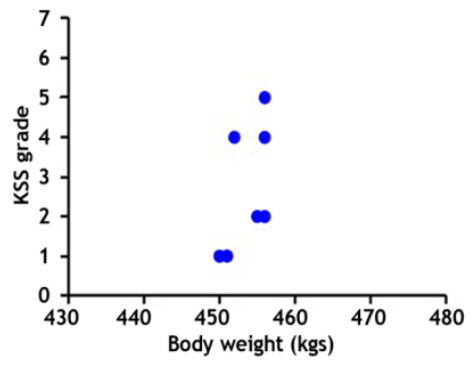

Figure 4. Correlation between body weight and grade of KSS in mares.

\section{DISCUSSION}

Horses are predisposed to back injuries because of the type of work and competition intensity that they are currently submitted to (Wyche, 2011). Thoroughbreds are more prone to back disorders, when compared to other breeds, because the tips of their spinous processes are closer to each other. Back injuries have great implications on the performance of the horse and rider, and they are associated with a complex and sometimes confusing clinical presentation (Jeffcott, 2010). The horse's natural sport kinetic is affected with the presence of back pain (De Cocq, 2009), and have a limited range of motion of the thoracic spine for dorsoventral flexion and extension compared with asymptomatic horses (Wennerstrand et al., 2004). The lack of significant differences of the evaluated radiological signs found in the segments considered for analysis is disputable. There is also no significant differences in the degree of KSS despite some mathematical trends. This is likely because the study population is homogeneous and possesses characteristics inherent to thoroughbred race horses. Furthermore, according to Zimmerman et al., (2012), thoroughbreds present a prevalence of $76 \%$ greater, as well as higher grading, of KSS than other horses breeds, in a study carried out on 572 horses. This is due to the narrower tops of the spinous processes in thoroughbred horses. According to Jeffcott \& Haussler (2004) more cases have been reported in thoroughbred horses due to ventroflexion and/or rider maneuvers caused by altered exercise biomechanics, predisposing to KSS. 
Sustainability Agri, Food and Environmental Research 4(4), 2016: 1-12

ISSN: 0719-3726

Although there are no significant radiological signs differences between groups, geldings presented a mathematical tendency to have higher interspinous space width, which contrasts with previous reports were they describe that thoroughbred geldings have a higher frequency of presentation of the syndrome, according to a study carried out on 110 horses (Henson \& Kidd 2009). Moreover, Zimmerman et al. (2012) found no significant association between gender, height and weight or clinical signs of thoracolumbar pain in a study carried out on 604 horses. Furthermore, the frequency of the syndrome is lower when wider spaces cranial and caudal to T15 are found (Turner, 2011).

Due to its particular anatomy, the horse's vertebral column is not designed to support significant weight on the spine. Because of a physiological and behavioral need created by man to bear weight, the equine vertebral column provides a combination of elasticity and rigidity during the biomechanics of exercise, which allows high speed activities to develop (Wyche, 2011). The need to carry weight causes the greatest impact on the area between T14 to T16, where the rider's weight is carried (Jeffcott \& Haussler, 2004). A greater presence of KSS was found in the central segments, which supports findings in previous studies, like Denoix \& Dyson (2010) wich found that the most common segment affected was T15-T16, followed by T14-T15 and T16T17.Furthermore, Erichsen et al. (2010), found a higher prevalence of the syndrome between T13T14, T14-T15, T15-T16, T16-T17 and T17-T18, and in a study carried out by Walmslay et al. (2010), the prevalence of the syndrome was greater in T15, followed by T16 and T17 in the thoracic segment.

The result of the number of affected DSPs per horse group is disputable, however, considering the findings of Henson \& Kidd (2009) that determined geldings present the syndrome more frequently. Furthermore, a radiographic evaluation between T11 to L2 in a study carried out by Turner (2011) resulted in an average of 4.3 overcrowded DSPs per horse, 88 horses presenting 5 or more DSPs affected and 124 had between 2 and 4 .

The distribution of the syndrome is similar in stallions but not in mares and geldings. According to Goodship \& Smith (2008), sex steroids play a role in homeostasis of bone metabolism; estrogens acts by decreasing bone resorption and testosterone is responsible for strength and bone density, which is why these differences between groups may occur. Furthermore, Perrone et al. (2006) proposed that sport horses are under constant physiological stress and drug and/or chemical substance administration because of their activity; this can depress the immune system, altering the homeostasis of androgens. Because of this, Pieter (2014) states that an 
Sustainability Agri, Food and Environmental Research 4(4), 2016: 1-12

ISSN: 0719-3726

examination covering other features, such as measurement of hormones and haematological profiles in the study groups, in order to assess changing levels of sex hormones, is necessary, as they can provide valuable information. These results can also allow that adequate food is provided for the activity of the horse, thus meeting the requirements of vitamins, minerals and protein needed, including bone metabolism.

The horses in this study were of similar ages, received similar training and standard medical care and maintenance. This supports the statement made by Butler et al. (2008), and Goodship \& Smith (2008), that the basic bone response to these stimuli is affected by diet, disease and the physiological state of other organs. They state that testing of bone metabolism and densitometry is required to determine the in situ activity of the bones and probable changes occurring since a previous diagnosis. In addition, Hughes (2010) noted that a radiological diagnosis of the spine can be associated with other forms of imaging to establish an accurate and complete diagnosis. Stubbs et al. (2010) noted that the thoracolumbar stability is provided by the epaxial and hypoaxial muscles in sport horses, so the development of these muscle groups has a protective factor against KSS, and small variations in them causes back changes in the sport horse. The interspinous and supraspinous ligaments generate stabilization between vertebral junctions. The vertebrae articulate caudally and cranially at the articular processes and intervertebral discs that are located on the vertebral body. All joints in the thoracolumbar region have limited mobility, making it difficult to detect changes when the horse is trained (Denoix \& Dyson, 2010).

Horses of this study showed evident radiological signs of KSS. The central segments of the thoracic spine (T14-T15 and T15-16) of the studied population have higher grades of radiological signs of KSS. Radiological signs among the evaluated segments have similar characteristics and location in stallions, geldings and mares evaluated in this study. Imaging examinations and laboratory tests, together with comprehensive assessments of the horse could lead to the application of treatments for KSS in Chile.

\section{REFERENCES}

Berner D, Wintert K, Brehm W, Gerlach K. 2012. Influence of head and neck position on radiographic measurement of intervertebral distances between thoracic dorsal spinous processes in clinically sound horses. EVJ. 44, Suppl. 43, 21-26. 
Sustainability Agri, Food and Environmental Research 4(4), 2016: 1-12 ISSN: 0719-3726

Budras K-D, Sack WO, Röck S. 2012. Axial Skeleton and Neck. Anatomy of the horse. 6th ed. Hannover, Germany: Schlütersche. p. 56-58.

Butler JA, Colles CM, Dyson SJ, Kold SE, Poulos PW.2008. Clinical Radiology of the Horse. 2nd ed. Oxford, UK: Blackwell. p. 403-456.

De Cocq P, Prinsen H, Springer N, Van Weeren P, Schreuder M, Muller M, Van Leeuwen JL. 2999. The effect of rising and sitting trot on back movements and head-neck position of the horse. EVJ. May, 41: 423-427.

Denoix J-M, Dyson SJ. 2010. Thoracolumbar Spine. Michael WR, Dyson SJ. Diagnosis and Management of Lameness in the Horse. 2nd ed. Missouri, USA: Elsevier;. 592-605.

Erichsen C, Eksell P, Roethlisberger HK, Lord P, Johnston C. 2010. Relationship between scintigraphic and radiographic evaluations of spinous processes in the thoracolumbar spine in riding horses without clinical signs of back problems. EVJ. 36: 458-465.

Goodship A, Smith R. 2008. Skeletal physiology: responses to excercise and training. Hinchcliff J, Geor R, Kanep A. Equine exercises physiology: 1st ed. Philadelphia, USA: Elsevier; p. 81-105.

Henson FMD, Kidd JA. 2009. Overriding dorsal spinous processes. Henson FMD. Equine back pathology: Diagnosis and treatment. 1st ed. Cambridge, UK: Wiley-Blackwell; p. 79-85.

Hughes KJ. 2010. Spinal radiography of the horse. EVJ. January, 19: 460-462.

Jeffcott LB. 2010. Back problems in the horse - A look at past, present and future progress. EVJ. April, 11: 129-136.

Jeffcott LB. 2005. Radiographic Features of the Normal Equine Thoracolumbar Spine. EVJ. May, 20: $140-147$.

Jeffcott LB, Haussler K. Equine sports medicine and surgery. 1st ed. Missouri, USA: Elsevier; 2004. p. 433-471.

Perrone GM, Caviglia JF, Perez A, Fidanza M, Marquez A, Catelli JL, González G. 2006. Cambios en las variables fisiológicas en equinos compitiendo en una prueba combinada. AN. VET. October, 22: $35-42$.

Pieter HL. The racehorse: A veterinary manual. 1ra ed. Cambridge, UK: CRC Press; 2014. p. 337340.

Sinding MF, Berg LC. 2010. Distances between thoracic spinous processes in Warmblood foals: a radiographic study. EVJ. September, 42: 500-3. 
Sustainability Agri, Food and Environmental Research 4(4), 2016: 1-12 ISSN: 0719-3726

Stubbs NC, Riggs CM, Hodges PW, Jeffcott LB, Hodgson DR, Clayton HM, McGowan CM. 2010. Osseous spinal pathology and epaxial muscle ultrasonography in Thoroughbred racehorses. EVJ. November, 2010; 38: 654-661.

Turner TA. Overriding Spinous Processes ("Kissing Spines") in Horses: Diagnosis, Treatment, and Outcome in 212 Cases. Proceedings of the 57th Annual Convention of the AAEP; November, 2011, $18-22$.

Walmslay JP, Pettersson H, Winberg F, McEvoy F. Impingment of the dorsal spinous processes in two hundred and fifteen horses: case selection, surgical technique and results. EVJ. January, 2010; 34: 23-28.

Wennerstrand J, Johnston C, Roethlisberger-Holm K, Erichsen C, Eksell P, Drevemo S. Kinematic evaluation of the back in the sport horse with back pain. EVJ. 2004; 36: 707-711.

Wyche S. Understanding the horse's back. 1ra ed. Wiltshire, Reino Unido: Crowood; 2011. p. 8-43. Zimmerman M, Dyson S, Murray R. Close, impinging and overriding spinous processes in the thoracolumbar spine: The relationship between radiological and scintigraphic findings and clinical signs. EVJ. March, 2012; 44:178-84. 